\title{
Age-dependent Glomerular Damage in the Rat Dissociation between Glomerular Injury and both Glomerular Hypertension and Hypertrophy. Male Gender as a Primary Risk Factor
}

\author{
Chris Baylis \\ Department of Physiology, West Virginia University, Morgantown, West Virginia 26506-9229
}

\begin{abstract}
The glomerulus develops progressive injury with advancing age which is particularly pronounced in males and is not the result of any specific disease process. In the present studies conducted in rats, glomerular function and structure were examined in adult $(8 \mathrm{mo})$, elderly $(12 \mathrm{mo})$, and old (19 mo) Munich Wistar rats. Intact males and females and castrated rats of both sexes were studied to determine the role of the sex hormones in mediating age-dependent glomerular damage. Intact males developed glomerular injury and proteinuria whereas females, both intact and ovariectomized, and castrated males were protected from injury. Glomerular blood pressure did not increase with advancing age in any group and did not correlate with glomerular damage. Glomerular volume did increase with advancing age in all groups but did not correlate with glomerular damage. We found that the presence of the androgens rather than the absence of the estrogens provide the risk factor for development of age-dependent glomerular damage. Neither glomerular hypertension nor glomerular hypertrophy provide the primary mechanism by which age-dependent glomerular injury occurs in the intact male. (J. Clin. Invest. 1994. 94:1823-1829.) Key words: ageing • glomerulus • glomerular blood pressure • glomerular volume • glomerular injury
\end{abstract}

\section{Introduction}

In men, glomerular filtration rate (GFR) ${ }^{1}$ begins a slow decline of $\sim 1 \%$ per year after the age of $40(1,2)$. Reductions in renal blood flow and renal plasma flow also occur with advancing

Sections of this study have been published in abstract form in Proceedings 11th Congr. Nephrol. 1990. 488; Kidney Int. 1990. 37:55; J. Am. Soc. Nephrol. 1990. 1:670, and 1:622.

Address correspondence to Chris Baylis, Department of Physiology, West Virginia University, PO Box 9229, Morgantown, WV 265069229.

Received for publication 11 April 1994 and in revised form 28 July 1994.

1. Abbreviations used in this paper: $\mathrm{BP}$, mean arterial blood pressure; $\mathrm{BW}$, body weight; GFR, glomerular filtration rate; $\mathrm{K}_{\mathrm{f}}$, glomerular ultrafiltration coefficient; $\mathrm{KW}$, kidney weight; $\mathrm{P}_{\mathrm{GC}}$, glomerular capillary blood pressure; $P_{T}$, proximal tubule hydrostatic pressure; $Q_{A}$, glomerular plasma flow; $R_{A}$, preglomerular arteriolar resistance; $R_{E}$, efferent arteriolar resistance; RPF, renal plasma flow; $S N$, single nephron; $U_{p} V$, urinary protein excretion; $\mathrm{V}_{\mathrm{g}}$, mean glomerular volume.

J. Clin. Invest.

(C) The American Society for Clinical Investigation, Inc. 0021-9738/94/11/1823/07 \$2.00

Volume 94, November 1994, 1823-1829 age $(3,4)$ and morphologic changes include focal and segmental glomerular sclerosis and a reduction in the number of functioning glomeruli $(1,2)$. This age-dependent decline in glomerular function occurs in the absence of any specific underlying renal disease and the rate of decline is sufficiently slow enough that it does not compromise overall renal function $(1,2)$. Because of these decremental hemodynamic changes, however, the aging kidney is at increased risk to develop toxic or ischemic acute renal failure, or chronic renal disease due to multiple causes including systemic hypertension (2). Spontaneous declines in glomerular function and structural injury also appear in the aging rat. Chronic renal disease is a major cause of death in some rat strains, although the incidence of age dependent glomerular damage is variable between strains (5-10). As with man, the kidney of the aging rat also shows an increased susceptibility to renal damage due to other causes (5).

There is good evidence that increases in glomerular capillary blood pressure $\left(\mathrm{P}_{\mathrm{GC}}\right)$ play a pathogenic role in a number of primary glomerular diseases (10). Certainly the presence of systemic hypertension in man accelerates the rate of age-dependent reductions in GFR $(1,2)$. In rats, modification of diet influences the rate of progression of primary glomerular diseases. Dietary protein restriction protects, and high dietary protein feeding exacerbates glomerular injury, by reducing and increasing $\mathrm{P}_{\mathrm{GC}}$ respectively (10). It is also well established that caloric and specifically protein restriction attenuate the rate of development of glomerular lesions in aging rat colonies $(5,10)$. Based on these observations, Anderson and Brenner (10) have suggested that age dependent glomerulopathy occurs secondary to age dependent increases in $P_{G C}(10)$.

In addition to diet, gender is another major determinant of the rate at which glomerular structural injury and derangements in renal hemodynamics occur with advancing age, since renal functional declines are delayed in females compared with males $(3,4,7)$. To further investigate the mechanisms of age-dependent glomerular injury we conducted the present studies in Munich Wistar rats aged from 7-20 mo. Measurements were made of glomerular hemodynamics, 24-h protein excretion, glomerular histologic injury and morphometric analysis of glomerular volumes in intact male rats. To investigate the sex difference, similar studies were also conducted in intact female rats. To gain further insight into the role of sex hormones in the pathogenesis of age dependent glomerular injury, additional studies were conducted in castrated rats of both sexes.

\section{Methods}

Studies were conducted on 95 Munich Wistar rats derived from a mycoplasma-free colony at Simonsen Laboratories (Gilroy, CA). Virgin rats of both sexes were selected at 8-10 wk of age and 50\% of males were castrated and $50 \%$ of females were ovariectomized. Rats were then aged up to $20 \mathrm{mo}$, under barrier conditions to eliminate air-borne diseases. 
Cohorts of rats were established over a 6-mo period and subgroups were taken out for study at the following ages; 7-9 mo ( $~ 8 \mathrm{mo}), 11-13$ mo ( $\sim 12 \mathrm{mo})$, and 18-20 mo ( $\sim 19 \mathrm{mo})$. Rats were shipped to our laboratory $2-4 \mathrm{wk}$ before study where they were maintained in positive pressure laminar flow hoods. Throughout their lives rats had ad libitum access to drinking water and standard rat chow containing $\sim 24 \%$ protein and $0.4 \% \mathrm{Na}$.

Before acute study, rats were placed in metabolic cages for collection of urine which was analyzed for total protein concentration, by the Bradford assay (11). On the day of micropuncture study, rats were anesthetized with ip thiobarbiturate $(100-120 \mathrm{mg} / \mathrm{kg}$ body weight) and placed on a temperature-regulated table to maintain core temperature at $36-38^{\circ} \mathrm{C}$ throughout the experiment. The left femoral artery was catheterized and used for periodic blood sampling and to monitor arterial blood pressure, by a pressure transducer connected to a recorder. The left femoral vein was cannulated for infusion of isoncotic artificial serum at $1 \%$ body weight per hour during the preparatory surgery and thereafter at $0.15 \%$ body weight $/ \mathrm{h}$, to maintain plasma volume (12). A tracheostomy was performed and the left jugular vein was catheterized for infusion of ${ }^{3} \mathrm{H}$-inulin $(100 \mu \mathrm{Ci} / \mathrm{ml} 0.9 \% \mathrm{NaCl}, \mathrm{NEN}$, Boston, MA) at $\sim 40 \mu \mathrm{Ci} / 100 \mathrm{~g}$ body weight per hour. A midline abdominal incision was made and the left kidney was prepared for micropuncture as described earlier (13). The left ureter was cannulated with PE10 for urine collection directly into graduated tubes. For measurement of $\mathrm{P}_{\mathrm{GC}}$ by the indirect, stop-flow pressure method, tubule fluid flow was stopped by insertion of paraffin wax blocks into 5-7 randomly selected, mid-proximal surface nephron segments.

After a 45-60-min equilibration period at the end of surgery, two (20-30 min) urine collections were made and midpoint femoral arterial blood samples were taken. Simultaneously, the following measurements and collections were made by micropuncture in the superficial renal cortex: $\mathrm{P}_{\mathrm{GC}}$ was measured by direct puncture of accessible superficial glomeruli $(n=2-4)$ and indirect $\mathrm{P}_{\mathrm{GC}}$ in deeper glomeruli was calculated from the stop-flow pressure + afferent arteriolar oncotic pressure $\left(\pi_{\mathrm{A}}\right)$. The stop-flow pressure was measured in the earliest segment proximal to the wax block in the 5-7 blocked tubules. In addition, hydrostatic pressure was measured in 2-3 efferent arterioles and in 10 proximal tubule segments $\left(\mathrm{P}_{\mathrm{T}}\right)$ by direct puncture with micropipettes $(2-4 \mu \mathrm{m}$ tip diameter), containing $1.2 \mathrm{M} \mathrm{NaCl}$ solution. These micropipettes formed part of a servonull micropressure measuring system (model 4a; Instruments for Physiology and Medicine, San Diego, CA) coupled to a pressure transducer and recorder. In addition, 5-6 exactly timed (2$4 \mathrm{~min}$ ) samples of fluid from superficial proximal tubules and samples of blood from 3-5 superficial efferent arterioles were collected. At the end of the experiment the left kidney was removed, weighed, sliced longitudinally, and fixed in $10 \%$ buffered formalin for later histology and morphometry studies.

Activity of ${ }^{3} \mathrm{H}$-inulin was counted in a liquid scintillation counter in the entire tubular fluid sample, in $5 \mu \mathrm{l}$ plasma samples and in $1-\mu \mathrm{l}$ urine samples. Total protein concentrations in postglomerular (efferent) arteriolar and systemic (femoral) arterial plasma samples were measured by a microadaption of the Lowry method (14). From these measurements, calculations were made of GFR, single nephron (SN) GFR, single nephron filtration fraction (SNFF), glomerular plasma flow $\left(Q_{A}\right)$, afferent and efferent arteriolar oncotic pressures $\left(\pi_{\mathrm{A}}\right.$ and $\pi_{\mathrm{E}}$ ), the glomerular ultrafiltration coefficient $\left(\mathrm{K}_{\mathrm{f}}\right)$, and preglomerular and efferent arteriolar resistances $\left(R_{A}\right.$ and $R_{E}$ ) as have been described previously (13). All statistical analyses of functional studies were performed using unpaired $t$ test or the appropriate analysis of variance (see Results). Statistical significance is defined as $P<0.05$, throughout. All values are expressed as mean \pm SEM.

After fixation, blocks of kidney tissue were dehydrated, embedded in paraffin, and 3- $\mu \mathrm{m}$ sections were cut and stained with periodic acid schiff with Harris hematoxylin counterstain. The tissues were coded and examined on a blinded basis by light microscopy for the degree of glomerular sclerosis. Injury was assessed using a 0-4 + scale (15) on 100 cortical glomeruli/section and each section was scored 2-3 times and the average used. Statistical evaluation of histologic data was by Wilcoxon rank sum analysis.

Mean glomerular volume $\left(\mathrm{V}_{\mathrm{g}}\right)$ was calculated for each rat, from the planar cross-sectional area of 50 undamaged cortical glomeruli, measured on a blinded basis. Details of this technique were reported previously (12). These $\mathrm{V}_{\mathrm{g}}$ measurements were made on immersion fixed tissue. It had previously been reported that immersion fixation with the slowly penetrating EM fixative (glutaraldehyde) gave erroneously low values for $\mathrm{V}_{\mathrm{g}}$ and that perfusion fixation was preferred (16). To test the validity of our use of immersion fixed tissue, using the rapidly penetrating fixative, formalin, we conducted additional studies in five young adult Sprague Dawley males. After induction of general anesthesia, one kidney was clamped at the pedicle, removed, sliced longitudinally, and placed in $10 \%$ buffered formalin. The other kidney was perfused for several minutes at $100 \mathrm{mmHg}$ with $10 \%$ buffered formalin, then removed and placed in $10 \%$ formalin. The average $\mathrm{V}_{\mathrm{g}}$ was measured on both kidneys from each of the rats. The mean value of $\mathrm{V}_{\mathrm{g}}$ for the group was similar in immersion fixed and perfusion fixed kidneys $(11.96 \pm 0.44$ and $11.71 \pm 0.62 \mu \mathrm{m}^{3} \times 10^{5}$, respectively), validating our use of kidneys fixed by immersion in formalin for $\mathrm{V}_{\mathrm{g}}$ measurement.

\section{Results}

Body weight (BW) remained constant in intact male Munich Wistar rats from 8-19 mo of age, whereas the wet left kidney weight $(\mathrm{KW})$ increased and was significantly higher at both 12 and 19 vs 8 mo (Table I). GFR and renal plasma flow (RPF) remained relatively stable with advancing age although a slight tendency to decline was noticed which was only significant at 12 vs 8 mo of age for GFR. When factored for kidney weight, however, GFR and RPF were lower at 19 vs 8 mo $(0.83 \pm 0.03$ vs $1.02 \pm 0.04 \mathrm{ml} / \mathrm{min}, P<0.05$ and $2.9 \pm 0.1$ vs $3.8 \pm 0.4 \mathrm{ml} /$ $\min , P=0.05$, respectively). The filtration fraction remained unchanged with advancing age (not shown). Mean arterial blood pressure (BP) did not change and remained in the normotensive range up to 19 mo of age. The $P_{G C}$ is shown for both superficial (directly measured) and deeper (indirectly measured) glomeruli in Fig. 1. There were no systematic differences between direct and indirectly measured values of $\mathrm{P}_{\mathrm{GC}}$, and there was no systematic change in either measure of $P_{G C}$ with advancing age. The average $\mathrm{P}_{\mathrm{GC}}$ from direct and indirect values, is shown in Table I and did not increase from 8 to 19 mo of age. $P_{T}$ also remained unchanged and therefore the transglomerular hydrostatic pressure difference was also constant (not shown). SNGFR and $\mathrm{Q}_{\mathrm{A}}$ tended to decline slightly with advancing age but this was only statistically significant at 12 vs 8 mo for SNGFR. Both $R_{A}$ and $R_{E}$ increased at 19 vs 8 mo of age but $K_{f}$ remained unchanged. There was a significant increase in total urinary protein excretion $\left(U_{p} V\right)$ at 19 mo of age which was accompanied by histologic evidence of glomerular damage, since the number of normal glomeruli declined. The $\mathrm{V}_{\mathrm{g}}$ increased substantially between 8 and 12 mo of age and remained elevated at 19 mo in intact males (Table I).

Table II summarizes studies conducted in normal intact female Munich Wistar rats. Both $\mathrm{BW}$ and $\mathrm{KW}$ increased slightly with advancing age. GFR and RPF did not change, even when factored for KW and similarly mean arterial blood pressure (BP), direct and indirect $P_{G C}$ (Fig. 1), and average $P_{G C}$ and $P_{T}$ remained unchanged up to 19 mo of age. SNGFR remained constant although a small increase occurred in $Q_{A}$ at 19 months and values of $R_{A}, R_{E}$, and $K_{f}$ did not change with age although a trend towards renal vasodilation was noted. Urinary protein excretion was low and remained constant with aging in intact 
Table I. Summary of Whole Kidney and Single Nephron Variables in Normal, Intact Male Munich Wistar Rats at $\sim 8, \sim 12$, and $\sim 19$ mo of Age

\begin{tabular}{|c|c|c|c|c|c|c|c|c|c|c|c|c|c|c|c|}
\hline & BW & KW & GFR & RPF & BP & $P_{G C}$ & $\mathbf{P}_{\mathbf{T}}$ & SNGFR & $\mathbf{Q}_{A}$ & $\mathbf{R}_{\mathrm{A}}$ & $\mathbf{R}_{\mathbf{E}}$ & $\mathbf{K}_{\mathbf{f}}$ & $\mathrm{U}_{\mathrm{p}} \mathbf{V}$ & NG & $\mathrm{vg}$ \\
\hline & \multicolumn{2}{|r|}{$g$} & \multicolumn{2}{|c|}{$\mathrm{ml} / \mathrm{min}$} & & $m m H g$ & & \multicolumn{2}{|c|}{$\mathrm{nl} / \mathrm{min}$} & dyn.cm ${ }^{-}$ & $\times 10^{10}$ & $\begin{array}{l}n L / m i n \\
m m H g\end{array}$ & $m g / 24 h$ & $\%$ & $\mu^{3} \times 10^{5}$ \\
\hline \multicolumn{16}{|c|}{$\sim 8 \mathrm{mo}(n=6)$} \\
\hline Mean & 387 & 1.34 & 1.4 & 5.2 & 98 & 52 & 13 & 55 & 225 & 0.88 & 0.80 & 0.063 & 29 & 93 & 11.22 \\
\hline$\pm \mathrm{SE}$ & 14 & 0.05 & 0.1 & 0.6 & 2 & 2 & 1 & 3 & 26 & 0.12 & 0.12 & 0.003 & 9 & 1 & 1.52 \\
\hline \multicolumn{16}{|c|}{$\sim 12 \mathrm{mo}(n=8)$} \\
\hline Mean & 396 & $1.51^{*}$ & $1.2^{*}$ & 4.5 & 93 & 49 & 12 & $44^{*}$ & 207 & 0.87 & 0.97 & 0.063 & 41 & 91 & $17.98 *$ \\
\hline$\pm \mathrm{SE}$ & 7 & 0.08 & 0.1 & 0.3 & 7 & 1 & 1 & 2 & 39 & 0.20 & 0.13 & 0.010 & 9 & 2 & 1.26 \\
\hline \multicolumn{16}{|c|}{$\sim 19$ mo $(n=8)$} \\
\hline Mean & 402 & $1.52 *$ & 1.3 & 4.5 & 103 & $52^{\ddagger}$ & 12 & 51 & 165 & $1.30^{*}$ & $1.18^{*}$ & 0.074 & $98^{* \neq}$ & $82^{* \ddagger}$ & $16.02^{*}$ \\
\hline$\pm \mathrm{SE}$ & 5 & 0.02 & 0.1 & 0.2 & 3 & 1 & 1 & 3 & 7 & 0.07 & 0.06 & 0.008 & 22 & 2 & 0.48 \\
\hline
\end{tabular}

* Differs from 8 mo $P<0.05 ;{ }^{\ddagger}$ differs from 12 mo $P<0.05$ by one way ANOVA.

females, as did the number of normal glomeruli, whereas $\mathrm{V}_{\mathrm{g}}$ increased at 12 vs 8 mo and this increase was maintained at 19 mo. In comparing the data derived from intact males vs intact females (by two-way ANOVA), males were heavier and KW was greater at all ages vs females $(P<0.001$ throughout $)$. GFR and RPF were always higher in males vs females $(P<0.001$ and $P<0.005$, respectively) and SNGFR and $\mathrm{Q}_{\mathrm{A}}$ were also higher in males at all ages $(P<0.001$ and $P<0.02$ respectively). There were no differences in $\mathrm{BP}$ or $\mathrm{P}_{\mathrm{T}}$ although the average value of $P_{G C}$ was slightly higher in males vs females at 19 mo of age $(P=0.05)$ (Tables I and II). At 8 mo of age, $\mathrm{R}_{\mathrm{A}}$ and $\mathrm{R}_{\mathrm{E}}$ were lower in males vs females (both $P<0.001$ ) as reported previously by us (17). This difference persisted at 12 mo of age (both $P<0.005$ ) but by 19 mo there was no difference in $R_{A}$ and $R_{E}$ between intact males and females.

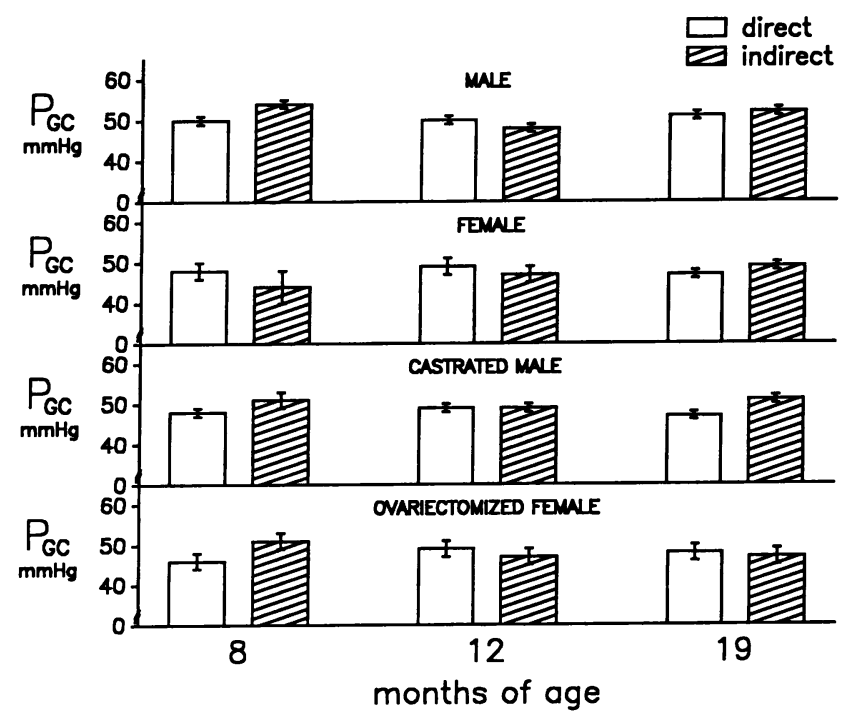

Figure 1. Glomerular blood pressure $\left(\mathrm{P}_{\mathrm{GC}}\right)$ measured by direct puncture in superficial glomeruli $(\square)$ and by the indirect stop flow method sampling from deeper cortical glomeruli (a) are given for rats at 8,12 , and 19 mo of age, respectively. Data are given for intact male (upper panel), intact female (second panel), castrated male (third panel), and ovariectomized female (fourth panel). Data given as mean \pm SE.
There were no differences in the value of $K_{f}$ between the sexes at any age. Female rats were always less proteinuric than males $(P<0.05$ at $8 \mathrm{mo} ; P<0.005$ at 12 and $19 \mathrm{mo}$ ), and had more normal glomeruli at 19 mo of age compared with males $(P$ $<0.002)$. $\mathrm{V}_{\mathrm{g}}$ was not different at $8 \mathrm{mo}$ but was larger in males vs females at 12 and 19 mo of age $(P<0.05$ and $<0.01$, respectively).

Table III summarizes data obtained in castrated male rats. No age-dependent changes were seen in $\mathrm{BW}, \mathrm{KW}$, or whole kidney hemodynamics. BP fell slightly at 12 mo of age but was not different between 8 and 19 mo of age and was in the normotensive range throughout. Similarly, $P_{G C}$ and $P_{T}$ remained at normal values over the aging period (Table III, Fig. 1). There were no changes in SNGFR, $Q_{A}, R_{A}$, or $R_{E}$ with advancing age in castrated male rats. $K_{f}$ may have fallen slightly after 8 mo of age, however, since the mean $\mathrm{K}_{\mathrm{f}}$ was calculated from minimum and unique values this reduction may have no biological significance. There was no increase in $U_{p} V$ or histologic evidence of glomerular damage over the entire aging period. However, $\mathrm{V}_{\mathrm{g}}$ increased significantly between 8 and 12 mo of age and remained elevated at 19 mo. In comparison between castrated and intact males, kidney weight was always higher in intact males $(P<0.001)$ although body weights were similar at all ages. In general, whole kidney and single nephron hemodynamics were similar in castrated and intact males at all ages with the exception that GFR was slightly lower and $R_{A}$ was slightly higher in castrated vs intact males at 8 mo of age ( $P$ $<0.02$ and $P<0.05$; respectively). Importantly, $\mathrm{P}_{\mathrm{GC}}$ was similar in intact and castrated males at all ages. The most striking difference was at 19 mo of age when castrated rats had significantly less proteinuria and less glomerular damage compared to intact males ( $P<0.005$ for both variables). The values of $\mathrm{V}_{\mathrm{g}}$ were similar between castrated and intact males at all ages.

Table IV summarizes data from ovariectomized female $\mathrm{Mu}$ nich Wistar rats. BW and KW remained stable up to 12 mo of age but increased slightly by 19 mo. BP, whole kidney, and single nephron glomerular hemodynamics remained unchanged in ovariectomized female rats over the entire aging period with the single exception that SNGFR was lower at 12 vs 8 mo (Table IV, Fig. 1). $U_{p} V$ remained low and the percentage of undamaged or normal glomeruli was unaffected by aging. $\mathrm{V}_{\mathrm{g}}$ increased from 8 to 12 mo of age and remained constant thereaf- 
Table II. Summary of Whole Kidney and Single Nephron Variables in Normal, Intact Female Munich Wistar Rats at $\sim 8, \sim 12$, and $\sim 19$ mo of Age

\begin{tabular}{|c|c|c|c|c|c|c|c|c|c|c|c|c|c|c|c|}
\hline & BW & KW & GFR & RPF & BP & $P_{G C}$ & $\mathbf{P}_{\mathrm{T}}$ & SNGFR & $\mathrm{Q}_{\mathrm{A}}$ & $\mathbf{R}_{\mathbf{A}}$ & $\mathbf{R}_{\mathrm{E}}$ & $\mathbf{K}_{\mathrm{f}}$ & $U_{p} V$ & NG & $\mathrm{Vg}$ \\
\hline & \multicolumn{2}{|c|}{$g$} & \multicolumn{2}{|c|}{$\mathrm{ml} / \mathrm{min}$} & & $\mathrm{mmHg}$ & & \multicolumn{2}{|c|}{$n l / \min$} & dyn.cm ${ }^{-}$ & $\times 10^{10}$ & $\begin{array}{l}\mathrm{nl} / \mathrm{min} / \\
\mathrm{mmHg}\end{array}$ & $m g / 24 h$ & $\%$ & $\mu^{3} \times 10^{5}$ \\
\hline \multicolumn{16}{|c|}{$\sim 8 \mathrm{mo}(n=8)$} \\
\hline Mean & 207 & 0.80 & 0.64 & 2.2 & 96 & 48 & 12 & 33 & 104 & 1.93 & 1.67 & 0.052 & 7 & 96 & 8.37 \\
\hline$\pm \mathrm{SE}$ & 5 & 0.03 & 0.04 & 0.1 & 5 & 1 & 1 & 2 & 6 & 0.12 & 0.08 & 0.004 & 1 & 2 & 0.62 \\
\hline \multicolumn{16}{|c|}{$\sim 12 \mathrm{mo}(n=9)$} \\
\hline Mean & $229 *$ & $0.97 *$ & 0.70 & 2.5 & 88 & 47 & 12 & 30 & 103 & 1.74 & 1.71 & 0.053 & 11 & 93 & $11.26 *$ \\
\hline$\pm \mathrm{SE}$ & 4 & 0.04 & 0.04 & 0.3 & 2 & 1 & 1 & 2 & 7 & 0.15 & 0.14 & 0.003 & 2 & 1 & 0.59 \\
\hline \multicolumn{16}{|c|}{$\sim 19 \mathrm{mo}(n=8)$} \\
\hline Mean & $242 *$ & $1.00 *$ & 0.77 & 3.1 & 94 & 48 & 13 & 33 & $133^{* \ddagger}$ & 1.51 & 1.38 & 0.051 & 16 & 92 & $12.36 *$ \\
\hline$\pm \mathrm{SE}$ & 5 & 0.03 & 0.07 & 0.4 & 3 & 1 & 1 & 3 & 10 & 0.10 & 0.11 & 0.006 & 4 & 1 & 0.67 \\
\hline
\end{tabular}

* Differs from 8 mo $P<0.05 ;{ }^{\ddagger}$ differs from 12 months $P<0.05$ by one way ANOVA.

ter. In comparison between intact and ovariectomized females one striking difference was that ovariectomized females were heavier than intact females at all ages (all $P<0.001)$ but there were no differences in KW. At 8 mo of age GFR and RPF were higher in ovariectomized vs intact females $(P<0.005$ and 0.01 , respectively) and although SNGFR was not different, $Q_{A}$ was also higher in ovariectomized females $(P<0.01)$. Both $\mathrm{R}_{\mathrm{A}}$ and $R_{E}$ were lower in ovariectomized vs intact females at 8 mo of age $(P<0.05$ and 0.01 , respectively) as reported by us earlier (17) but this difference disappeared with advancing age. All other variables including $\mathrm{BP}, \mathrm{P}_{\mathrm{GC}}$, and $\mathrm{U}_{\mathrm{p}} \mathrm{V}$ were similar at all ages in intact and ovariectomized females. The glomeruli were structurally normal in ovariectomized as well as intact females and values of $\mathrm{V}_{\mathrm{g}}$ were similar in intact and ovariectomized females at each age.

A four-way comparison at 19 mo of age showed that there was significantly more glomerular damage and proteinuria in intact males compared with all other groups. Table V summarizes histologic data for 19-mo-old rats and shows the severity of glomerular damage in the four groups. Glomerular injury was generally focal and segmental in all groups. There were fewer undamaged glomeruli in intact males compared with the other three groups. The $1+$ and $2+$ grades of injury (which correspond to $<25$ and $50 \%$ injury, respectively) were similar in all four groups, however, the most severe levels of glomerular injury, 3+ and 4+ appeared more frequently in intact males compared to the other three groups. By four-way analysis, values of $\mathrm{P}_{\mathrm{GC}}$ were similar in the four groups at 19 mo of age (Tables I-IV, Fig. 1), and $V_{g}$ was larger in intact males vs intact and ovariectomized females (both $P<0.05$ ) but not different to the castrated male.

\section{Discussion}

In this study we have demonstrated that intact male Munich Wistar rats develop a slowly evolving glomerular structural injury by 19 mo of age. It is well established that glomerular capillary hypertension plays a causal role in the development of various glomerulopathies and Anderson and Brenner (10) have suggested that age dependent glomerular damage results from high $\mathrm{P}_{\mathrm{GC}}$. In the present study however, we measured glomerular hemodynamics at intervals during aging and found no evidence that increased $P_{G C}$ preceded or was causally related to the development of glomerular structural injury. This finding

Table III. Summary of Whole Kidney and Single Nephron Variables in Castrated Male Munich Wistar Rats at $\sim 8, \sim 12$, and $\sim 19$ mo of Age

\begin{tabular}{|c|c|c|c|c|c|c|c|c|c|c|c|c|c|c|c|}
\hline & BW & KW & GFR & RPF & BP & $P_{G C}$ & $\mathbf{P}_{\mathrm{T}}$ & SNGFR & $\mathrm{Q}_{\mathrm{A}}$ & $\mathbf{R}_{\mathrm{A}}$ & $\mathbf{R}_{\mathbf{F}}$ & $\mathbf{K}_{\mathrm{f}}$ & $\mathrm{U}_{\mathrm{p}} \mathrm{V}$ & NG & $\mathrm{Vg}$ \\
\hline & \multicolumn{2}{|c|}{$g$} & \multicolumn{2}{|c|}{$\mathrm{mL} / \mathrm{min}$} & & $m m H g$ & & \multicolumn{2}{|c|}{$\mathrm{nL} / \mathrm{min}$} & dyn.cm & $\times 10^{10}$ & $\begin{array}{l}\mathrm{nl} / \mathrm{min} / \\
\mathrm{mmHg}\end{array}$ & $m g / 24 h$ & $\%$ & $\mu^{3} \times 10^{5}$ \\
\hline \multicolumn{16}{|c|}{$\sim 8 \operatorname{mo}(n=7)$} \\
\hline Mean & 377 & 1.05 & 1.14 & 4.08 & 99 & 49 & 13 & 50 & 176 & 1.24 & 1.04 & 0.082 & 15 & 93 & 9.17 \\
\hline$\pm \mathrm{SE}$ & 5 & 0.03 & 0.03 & 0.25 & 2 & 1 & 1 & 2 & 18 & 0.11 & 0.09 & 0.008 & 3 & 1 & 0.99 \\
\hline \multicolumn{16}{|c|}{$\sim 12 \mathrm{mo}(n=8)$} \\
\hline Mean & 371 & 1.09 & 1.05 & 4.39 & $91 *$ & 49 & 13 & 43 & 182 & 1.06 & 1.05 & $0.058 *$ & 21 & 92 & $15.76^{*}$ \\
\hline$\pm \mathrm{SE}$ & 9 & 0.06 & 0.10 & 0.41 & 2 & 1 & 1 & 3 & 22 & 0.11 & 0.11 & 0.004 & 5 & 2 & 0.92 \\
\hline \multicolumn{16}{|c|}{$\sim 19$ mo $(n=8)$} \\
\hline Mean & 387 & 1.12 & 1.10 & 4.83 & $98^{\ddagger}$ & 50 & 12 & 44 & 196 & 1.14 & 1.08 & $0.058 *$ & 23 & 90 & $13.65^{*}$ \\
\hline$\pm \mathrm{SE}$ & 6 & 0.04 & 0.07 & 0.57 & 3 & 1 & 1 & 3 & 26 & 0.09 & 0.14 & 0.006 & 3 & 1 & 0.86 \\
\hline
\end{tabular}

* Differs from 8 mo $P<0.05 ;{ }^{\ddagger}$ differs from 12 mo $P<0.05$ by one way ANOVA. 
Table IV. Summary of Whole Kidney and Single Nephron Variables in Ovariectomized Female Munich Wistar Rats at $\sim 8, \sim 12$, and $\sim 19$ mo of Age

\begin{tabular}{|c|c|c|c|c|c|c|c|c|c|c|c|c|c|c|c|}
\hline & BW & KW & GFR & RPF & BP & $P_{G C}$ & $\mathbf{P}_{\mathrm{T}}$ & SNGFR & $Q_{A}$ & $\mathbf{R}_{\mathrm{A}}$ & $\mathbf{R}_{\mathbf{F}}$ & $\mathbf{K}_{\mathrm{f}}$ & $\mathrm{U}_{\mathrm{p}} \mathrm{V}$ & NG & $\mathrm{Vg}$ \\
\hline & \multicolumn{2}{|c|}{$g$} & \multicolumn{2}{|c|}{$\mathrm{ml} / \mathrm{min}$} & & $m m H g$ & & \multicolumn{2}{|c|}{$n V / \min$} & dyn.cm ${ }^{5}$ & $\times 10^{10}$ & $\begin{array}{l}\mathrm{nl} / \mathrm{min} / \\
\mathrm{mmHg}\end{array}$ & $m g / 24 h$ & $\%$ & $\mu^{3} \times 10^{5}$ \\
\hline \multicolumn{16}{|c|}{$\sim 8 \mathrm{mo}(n=9)$} \\
\hline Mean & 278 & 0.82 & 0.79 & 2.79 & 97 & 50 & 13 & 38 & 140 & 1.50 & 1.28 & 0.053 & 10 & 93 & 8.02 \\
\hline$\pm \mathrm{SE}$ & 6 & 0.03 & 0.03 & 0.16 & 2 & 2 & 1 & 1 & 10 & 0.15 & 0.10 & 0.010 & 3 & 1 & 0.65 \\
\hline \multicolumn{16}{|c|}{$\sim 12 \mathrm{mo}(n=8)$} \\
\hline Mean & 279 & 0.86 & 0.69 & 2.74 & 92 & 48 & 13 & $30^{*}$ & 121 & 1.79 & 1.60 & 0.038 & 8 & 93 & $13.01 *$ \\
\hline$\pm \mathrm{SE}$ & 3 & 0.03 & 0.06 & 0.25 & 2 & 2 & 1 & 2 & 14 & 0.36 & 0.16 & 0.008 & 1 & 1 & 0.45 \\
\hline \multicolumn{16}{|c|}{$\sim 19 \operatorname{mo}(n=8)$} \\
\hline Mean & $302^{* \pm}$ & $0.92 *$ & 0.81 & 3.66 & 92 & 48 & 14 & 32 & 150 & 1.53 & 1.39 & 0.061 & 13 & 91 & $12.89 *$ \\
\hline $\pm S E$ & 7 & 0.03 & 0.09 & 0.43 & 2 & 2 & 1 & 3 & 25 & 0.24 & 0.17 & 0.013 & 2 & 1 & 0.68 \\
\hline
\end{tabular}

* Differs from 8 mo $P<0.05 ;{ }^{\ddagger}$ differs from 12 mo $P<0.05$ by one way ANOVA.

agrees with earlier observations by us in male Sprague Dawley rats studied at 20-22 mo of age; these rats exhibited substantial glomerular damage but had no increase in $P_{G C}$ (12). An unusual substrain of the Munich Wistar, the MWF/ZTM exhibits rapidly, spontaneously developing glomerular injury in the male which apparently represents an accelerated kidney aging process and in these rats $P_{G C}$ is normal (18). By 24 mo of age, $P_{G C}$ is elevated in superficial glomeruli of male Munich Wistar rats and chronic treatment with converting enzyme inhibitor prevents the high $P_{G C}$ and attenuates the glomerular injury (19). These observations have been interpreted as support for a primary role of increased $\mathrm{P}_{\mathrm{GC}}$ in development of age dependent glomerulopathy. However, given the present findings and earlier observations $(12,18)$, it seems more likely that the late rise in $\mathrm{P}_{\mathrm{GC}}$ is a secondary, compensatory response to glomerular damage, and that CEI evokes its beneficial effects via other, nonhemodynamic mechanisms (19).

In the Sprague Dawley rat, glomerular injury generally develops at a more accelerated pace than in Wistars (7) and in Sprague-Dawley's, small increases in $\mathrm{P}_{\mathrm{GC}}$ have been reported at $13-15$ and 18 mo of age $(9,20)$, (although not at 20-22 mo, [12]) which could contribute to the increased tendency of this strain to develop glomerular injury. In the Nagase strain of analbuminemic rats, there is no evidence of age dependent glomerular injury by 18 mo of age and these animals also exhibit lower than normal values of $P_{G C}(9)$. This, together with the wealth of evidence suggesting that systemic hypertension worsens age-dependent glomerular injury $(1,2,5,10)$, implies that when increases in $\mathrm{P}_{\mathrm{GC}}$ do occur, they will exacerbate the underlying development of age-dependent glomerular injury. However, the present studies in the male Munich Wistar rat show that glomerular damage will develop in the absence of glomerular capillary hypertension, thus high $\mathrm{P}_{\mathrm{GC}}$ cannot be the primary cause.

Rather than implicating a role for increases in $\mathrm{P}_{\mathrm{GC}}$ in age dependent glomerulopathy, perhaps exposure of the delicate glomerular capillary to normal $\mathrm{P}_{\mathrm{GC}}$, over a lifetime, provides the damaging stimulus? We gained further insight into this question by investigating the sex difference in rate of kidney aging. In the present study we observed that female Munich Wistar rats aged over a similar time period to males did not develop glomerular damage or proteinuria. Similar findings have been reported by others $(7,21)$ and clinical studies suggest that female human kidneys are also protected against age-dependent declines in renal hemodynamics and appearance of glomerular injury $(3,4)$. This sex-specific protection of the glomerulus is not limited to age-dependent glomerulopathy but is evident in the greater susceptibility of the male to develop ablation-induced glomerular damage $(22,23)$. Also, males but not females develop the spontaneous glomerular lesion seen in the MWF/ ZTN substrain of Munich Wistar rats $(18,24)$. This sex difference is clinically relevant since the rate of progression towards end stage renal failure in autosomal dominant polycystic kidney disease is significantly slower in women vs men (25). Men are at increased risk to develop end stage renal disease secondary to diabetes and hypertensive complications $(26,27)$ and long

Table V. Summary of Histologic Glomerular Injury Data for 19-mo-old Rats

\begin{tabular}{|c|c|c|c|c|c|}
\hline Injury grade & 0 & $1+$ & $2+$ & $3+$ & $4+$ \\
\hline Intact male $(n=8)$ & $82.4 \pm 1.5$ & $7.0 \pm 0.9$ & $2.8 \pm 0.3$ & $2.4 \pm 0.4$ & $5.1 \pm 0.6$ \\
\hline Intact female $(n=8)$ & $91.9 \pm 1.3^{*}$ & $5.8 \pm 0.8$ & $1.1 \pm 0.4$ & $0.5 \pm 0.2 *$ & $0.8 \pm 0.3 *$ \\
\hline Castrated male $(n=8)$ & $90.2 \pm 1.1^{*}$ & $5.3 \pm 0.5$ & $2.1 \pm 0.6$ & $0.5 \pm 0.2 *$ & $1.9 \pm 0.6 *$ \\
\hline OVX female $(n=8)$ & $90.5 \pm 0.9 *$ & $6.3 \pm 0.5$ & $2.1 \pm 0.4$ & $0.6 \pm 0.2^{*}$ & $0.6 \pm 0.1 *$ \\
\hline
\end{tabular}

${ }^{*} P<0.001$ vs intact male by Wilcoxon rank sum analysis. This data is expressed in terms of the $0-4+$ glomerular injury scale (17): 0 , no damage; $1+$, focal damage involving $<25 \%$ of the glomerulus; $2+$, focal damage, between $25-50 \%$ of the glomerulus; $3+$, widespread damage involving $50-75 \%$ of the glomerulus; $4+$, widespread damage involving $75-100 \%$ of the glomerulus and includes obsolescent glomeruli. 
term followup on kidney donors have indicated a greater incidence of hypertension and proteinuria in males vs female donors (28). We had earlier reported that the kidney of the young adult female is vasoconstricted relative to that of the male and in particular has a higher value of $R_{A}(17)$. At that time we speculated that this elevated $R_{A}$ might protect the female from increased $\mathrm{P}_{\mathrm{GC}}$ thus accounting for the sex dependent protection exhibited by females in aging, ablation, etc. induced glomerular injury (17). In an earlier study we reported that $P_{G C}$ was higher ( $5 \mathrm{mmHg}$ ) in male vs female rats several months after uniehrectomy and high dietary protein feeding (22). In the present study, however, we found that despite the higher values for $\mathbf{R}_{A}$ in females, $\mathrm{P}_{\mathrm{GC}}$ was similar in females and males at 8 and 12 mo and only slightly elevated in males at 19 mo of age. In castrated males and ovariectomized females there were no differences in $\mathrm{P}_{\mathrm{GC}}$ vs intact males at any age and yet only intact males developed glomerular damage. Thus, our present observations argue against a primary hemodynamic mechanism for development of age-dependent glomerular injury.

It has been suggested that hypertrophy of the glomerular tuft provides a separate risk factor for development of glomerular injury by increased intramural tension (29-31). In the present study we measured glomerular volumes and observed an increase in volume in intact male rats from 8-12 mo of age, which preceeded the development of the injury. Also, we found that the glomerular volumes of female rats were substantially lower than those of males at all ages. In the substrain of Munich Wistar rats MWF/ZTN where the males develop spontaneous injury and proteinuria, morphometric analysis showed an increase in glomerular volume in male but not female glomeruli (24). Thus, there is circumstantial evidence to suggest a role of glomerular hypertrophy in development of age- and sexdependent glomerular injury. However, we also conducted studies on castrated males and observed that glomerular volumes increased in castrated as in intact males, but that this increase in volume was not associated with the development of injury in castrated rats. This persistent increase in $V_{g}$ with age in castrated males was unexpected since the androgens promote kidney growth $(31,32)$. However, the renotrophic action of testosterone appears to be specific for tubular elements in rats with two kidneys (33) although androgens do contribute to the glomerular hypertrophy that occurs after reduction of renal mass (34). In the setting of reduction in renal mass, androgen-induced glomerular hypertrophy correlates with increased injury (34). The observations from the present studies suggest that aginginduced glomerular injury is caused by a different mechanism to glomerulopathy due to ablation.

Thus, whereas it is clear that both glomerular hypertension and glomerular hypertrophy can produce glomerular injury in some situations, the present studies in the aging Munich Wistar rat suggest that neither of these risk factors provide the primary mechanism for the development of age-dependent glomerulopathy in intact males. Based on our castration data and since ovariectomy does not alter the protected status of the intact female, it seems that either directly or indirectly, the presence of the androgens, rather than the absence of ovarian hormones, causes glomerular damage in intact males. Castration has previously been reported to protect male rats from development of glomerular injury following uninephrectomy, although this maneuver was also associated with a reduction in glomerular volume (35).

The cause of age-dependent glomerular damage in intact males has not been determined by the present studies. There is evidence to suggest that mesangial matrix accumulation plays a pathogenic role in immune-mediated and ablation-induced glomerular injury $(36,37)$. The increased susceptibility of the male to development of glomerular sclerosis after subtotal nephrectomy correlates with mesangial expansion and higher levels of glomerular procollagen mRNA levels in male vs female kidneys (23). Earlier observations by others suggest that aging is associated with mesangial hypertrophy and/or an excessive accumulation of mesangial matrix products. Mesangial lesions (38) and mesangial expansion (39) preceed the development of focal glomerular sclerosis due to aging and increases in mesangial matrix products have been reported in aging male but not female Wistar rats (21). In the Wistar/Lou strain, no age dependent glomerular injury develops and morphometric studies show no increase in mesangial matrix or mesangial cellularity in males up to 36 mo of age and females up to 42 mo of age (8). Mesangial matrix products can accumulate both because of increased synthesis and/or reduced rates of degradation (3840). We have recently reported that a neutral glomerular metalloprotease, one of the enzymes responsible for degradation of mesangial matrix products, increases markedly with aging in intact and ovariectomized females and castrated male rats all of whom are protected from injury. In contrast, there is no increase in metalloprotease activity in intact males who do exhibit damage (41). In addition to accumulation of mesangial matrix material, Remuzzi and colleagues have suggested that defects in glomerular permeability to macro-molecules cause proteinuria which leads to injury (42) and this may be the basis for the spontaneous injury that develops in male (but not female) MWF/ZTN rats (18).

In summary, our studies demonstrate that age-dependent glomerulopathy proceeds and develops in the absence of increases in $\mathbf{P}_{\mathrm{GC}}$. Further, glomerular hypertrophy is unlikely to provide the primary explanation for development of age dependent injury. The frequently reported sex difference in development of age-dependent glomerular damage (males susceptible) is the result of male gender since castration of the male is protective. The relative protection in females is unlikely to result from female gender since ovariectomy has no effect on glomerular structure with advancing age.

\section{Acknowledgments}

The excellent technical assistance of Kevin Engels, Lennie Samsell, Julie Boles, and Alea Palmer and secretarial assistance of Lisa Bradley are all gratefully acknowledged. I am also grateful to Simonsen Laboratories Inc. for their help in maintaining the aging Munich Wistar rats.

These studies were supported by National Institutes of Health grant DK-39963.

\section{References}

1. Lindeman, R. D., and R. Goldman. 1986. Anatomic and physiologic age changes in the kidney. Exp. Gerontol. 21:379-406.

2. Levi, M., and J. W. Rowe. 1992. Renal function and dysfunction in aging. Ch. 101 In The Kidney: Physiology and Pathophysiology. D. W. Seldin, and G. Giebisch, editors. Raven Press, New York. 3433-3456.

3. Wesson, L. G., Jr. 1969. Renal hemodynamics in physiological states. In Physiology of the Human Kidney Grune and Stratton, New York. 96-108.

4. Hollenberg, N. K., D. F. Adams, H. S. Solomon, A. Rashid, H. L. Abrams, and J. P. Merrill. 1974. Senescence and the renal vasculature in normal man. Circ. Res. 34:309-316.

5. Goldstein, R. S., J. B. Tarloff, and J. B. Hook. 1988. Age-related nephropathy in laboratory rats. FASEB (Fed. Am. Soc. Exp. Evol.) J. 2:2241-2251. 
6. Baylis, C., M. Fredericks, C. Wilson, K. Munger, and R. Collins. 1990. Renal vasodilatory response to intravenous glycine in the aging rat kidney. Am. J. Kidney Dis. 15:244-251.

7. Gray, J. E., M. J. van Zwieten, and C. F. Hollandes. 1982. Early light microscopic changes of chronic progressive nephrosis in several strains of aging laboratory rats. J. Gerontol. 37:142-150.

8. Dodane, V., J. Chevalier, J. Bariety, J. Pratz, and B. Corman. 1991. Longitudinal study of solute excretion and glomerular ultrastructure in an experimental model of aging rats free of kidney disease. Lab. Invest. 64:377-391.

9. Fujihara, C. K., D. M. Z. P. Limongi, H. C. F. De Oliveira, and R. Zatz. 1992. Absence of focal glomerulosclerosis in aging analbuminemic rats. Am. J. Physiol. 262:R947-R954.

10. Anderson, S., and B. M. Brenner. 1986. Effects of aging on the renal glomerulus. Am. J. Med. 80:435-442.

11. Bradford, M. M. 1976. A rapid and sensitive method for the quantitation of microgram quantities of protein utilizing the principle of protein-dye binding. Anal. Biochem. 72:248-254.

12. Reckelhoff, J. F., L. Samsell, R. Dey, L. Racusen, and C. Baylis. 1992. The effect of aging on glomerular hemodynamics in the rat. Am. J. Kid. Dis. 20:70-75.

13. Baylis, C., W. M. Deen, B. Myers, and B. M. Brenner. 1976. Effects of some vasodilator drugs on transcapillary fluid exchange in renal cortex. Am. J. Physiol. 230:1148-1158.

14. Lowry, O. H., N. J. Rosebrough, A. J. Farr, and R. J. Randall. 1951 Protein measurement with the folin phenol reagent. J. Biol. Chem. 193:265-275.

15. Raij, L., S. Azar, and W. Keane. 1984. Mesangial immune injury, hypertension and progressive glomerular damage in Dahl rats. Kidney Int. 26:137-143.

16. Miller, P. L., and T. W. Meyer. 1990. Effects of tissue preparation on glomerular volume and capillary structure in the rat. Lab. Invest. 63:862-866.

17. Munger, K., and C. Baylis. 1988. Sex differences in renal hemodynamics in rats. Am. J. Physiol. 254:F223-F231.

18. Remuzzi, A., S. Puntorieri, A. Mazzoleni, and G. Remuzzi. 1988. Sex related differences in glomerular ultrafiltration and proteinuria in Munich Wistar rats. Kidney Int. 34:481-486.

19. Anderson, S., H. G. Rennke, M. M. Santos, and R. Zatz. 1990. Glomerular adaptations with normal aging and with longterm converting enzyme inhibitor (CEI) therapy. Kidney Int. 37:498 (Abstr.).

20. Reckelhoff, J. F., and R. D. Manning, Jr. 1993. Role of endotheliumderived nitric oxide in control of renal microvasculature in aging male rats. Am. J. Physiol. 265:R1126-R1131.

21. Yee, W. W., S. Takahashi, and S. Kawashima. 1989. Age-related changes and sex difference in the ultrastructure of renal glomerulus in Wistar/Tw rats. Zoological Sci. 6:777-788.

22. Baylis, C., and C. B. Wilson. 1989. Sex and the single kidney. Am. J. Kid. Dis. 13:290-298.

23. Lombet, J. R., S. G. Adler, P. S. Anderson, C. C. Nast, D. R. Olsen, and R. J. Glassock. 1989. Sex vulnerability in the subtotal nephrectomy model of glomerulosclerosis in the rat. J. Lab. Clin. Med. 114:66-74.

24. Remuzzi, A., S. Puntorieri, M. Alfano, D. Macconi, M. Abbate, T. Bertani, and G. Remuzzi. 1992. Pathophysiologic implications of proteinuria in a rat model of progressive glomerular injury. Lab. Invest. 67:572-579.
25. Gretz, N., M. Zeier, S. Geberth, M. Strauch, and E. Ritz. 1989. Is gender a determinant for evolution of renal failure? A study of autosomal dominan polycystic kidney disease. Am. J. Kid. Dis. 14:178-183.

26. West, K. M., L. Erdreich, and J. A. Stober. 1980. A detailed study of risk factors for retinopathy and nephropathy in diabetes. Diabetes 29:501-508.

27. USRDS Annual data report. 1990. Am. J. Kidney Dis. 16(Suppl. 2):2227.

28. Hakim, R. M., R. C. Goldser, and B. M. Brenner. 1984. Hypertension and proteinuria: Long-term sequelae of uninephrectomy in humans. Kidney Int. 25:930-936.

29. Yoshida, Y., A. Fogo, and I. Ichikawa. 1989. Glomerular hemodynamic changes vs hypertrophy in experimental glomerular sclerosis. Kidney Int. 35:654 660.

30. Daniels, B. S., and T. H. Hostetter. 1990. Adverse effects of growth in the glomerular microcirculation. Am. J. Physiol. 258:F1409-F1416.

31. Jean-Faucher, C. H., M. Berger, C. H. Gallon, M. de Turckheim, G. Veyssiere, and C. I. Jean. 1987. Sex-related differences in renal size in mice: ontogeny and influence of neonatal androgens. J. Endocrinol. 115:241-246.

32. Blantz, R. C., O. W. Peterson, E. R. Blantz, and C. B. Wilson. 1988 Sexual differences in glomerular ultrafiltration: effect of androgen administration in ovariectomized rats. Endocrinology. 122:767-773.

33. Oudar, O., M. Elger, L. Bankir, D. Ganten, U. Ganten, and W. Kriz. 1991. Differences in rat kidney morphology between males, females and testosteronetreated females. Renal Physiol. Biochem. 14:92-102.

34. Lax, D. S., J. A. Benstein, E. Tolbert, and L. D. Dworkin. 1992. Effects of salt restriction on renal growth and glomerular injury in rats with remnant kidneys. Kidney Int. 41:1527-1534.

35. Gafter, U., M. Ben-Bassat, and J. Levi. 1990. Castration inhibits glomerular hypertrophy and proteinuria in uninephrectomized male rats. Eur. J. Clin. Invest. 20:360-365.

36. Lovett, D. H., R. J. Johnson, H-P. Marti, J. Martin, M. Davies, and W. G. Couser. 1992. Structural characterization of the mesangial cell type IV collagenase and enhanced expression in a model of immune complex-mediated glomerulonephritis. Am. J. Pathol. 141:85-98.

37. Floege, J., C. E. Alpers, M. W. Burns, P. Pritzl, K. Gordon, W. G. Couser, and R. J. Johnson. 1992. Glomerular cells, extracellular matrix accumulation, and the development of glomerulosclerosis in the remnant kidney model. Lab. Invest 66:485-497.

38. Couser, W. G., and M. M. Stilmant. 1975. Mesangial lesions and focal glomerular sclerosis in the aging rat. Lab. Invest. 33:491-501.

39. O'Donnell, M. P., B. L. Kasiske, L. Raij, and et al. 1984. Effect of aging on glomerular hemodynamics and morphology. Proc. Int. Congr. Nephrol. 397 (Abstr.).

40. Davies, M., G. A. Coles, G. J. Thomas, J. Martin, and D. H. Lovett 1990. Proteinases and the glomerulus: Their role in glomerular diseases. Klin. Wochenschr. 68:1145-1149.

41. Reckelhoff, J. F., and C. Baylis. 1993. Glomerular metalloprotease activity in the aging rat kidney: inverse correlation with injury. J. Am. Soc. Nephrol. 3:1835-1838.

42. Remuzzi, G., and T. Bertani. 1990. Is glomerulosclerosis a consequence of altered glomerular permeability to macromolecules? Kidney Int. 38:384-394. 